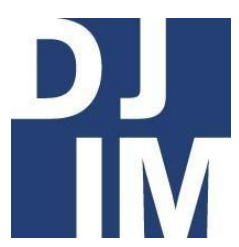

Volume 15

Spring

2019

djim.management.dal.ca |

\title{
Dutcher's Impact: Wolastioqiyik Lintuwakonawa as a Case Study for the role of Music in Preserving Traditional Knowledge
}

\author{
Kathryn E. Newhook
}

School of Information Management, Dalhousie University

\begin{abstract}
Knowledge Management is a diverse field of study, dealing in the facilitation of knowledge sharing, the creation of knowledge systems, knowledge transfer, and knowledge preservation. Information professionals play an important role in helping these processes happen. Equally important is the preservation of Traditional Knowledge. Recognized as the knowledge Indigenous people have accrued over millennia, and formed through their interactions with their environment, Traditional Knowledge and its preservation also fall into the world of Knowledge Management. The performance of a piece of music is the manifestation of knowledge and, in the case of Jeremy Dutcher, is a form of knowledge preservation. Traditional Knowledge's more fluid and dynamic nature is preserved in Dutcher's 2018 album Wolastioqiyik Lintuwakonawa, where the artist creates a conversation between technical skill and the knowledge and language of the album. In the case of this paper, Dutcher's album serves as an example of the way Traditional Knowledge can impact and provide new tools to the information profession and world of Knowledge Management.
\end{abstract}

Keywords: Knowledge Management, Music, Language, Traditional Knowledge, Jeremy Dutcher

In 2018, Jeremy Dutcher released an album entitled Wolastoqiyik Lintuwakonawa. It is an album of indigenous songs recorded in their original language grouping of the Maliseet-Passamaquoddy dialect of the Algonquin linguistic group (Government of 
New Brunswick, 2018). Dutcher's album is remarkable for its seamless combination of Wolastoq First Nations lyrics and melodies which are paired against a classically western compositional style. A classically trained operatic tenor and composer, Dutcher, through his album is an emotional exploration of his own Wolastoq roots and the power of music as a method of communicating meaning. Dutcher has created a vital, valuable tool for preserving the endangered language of the Wolastoq people, and communicating and transmitting the emotional, or tacit, intent of the music, even to people who do not speak Wolastoqey. Dutcher's album, at its core, is a tool in the project of Knowledge Management involving Indigenous people and heritage.

\section{Background}

Knowledge Management (KM) is an incredibly diverse field of study. Beyond the facilitation of knowledge sharing, KM includes the creation and cultivation of knowledge storage systems and strategies, knowledge transfers, and knowledge preservation. In a 1999 article "What is knowledge management?", Jennifer Rowley discusses answers to the questions "what is knowledge?" and "what is Knowledge Management?". In her answers to these questions, Rowley identifies what she terms "branches of project objectives" (p.416) that are at the root of a KM program. According to Rowley, the four main objectives of $\mathrm{KM}$ are;
(1) "To create knowledge repositories, which store both knowledge and information, often in documentary form. A common feature is "added value" through categorisation and pruning;

(2) To improve knowledge access, or to provide access to knowledge or to facilitate its transfer amongst individuals; here the emphasis is on connectivity, access, and transfer;

(3) To enhance the knowledge environment, so that the environment is conducive to more effective knowledge creation, transfer, and use;

(4) To manage knowledge as an asset, and to recognise the value of knowledge to an organisation." (p. 416-7).

These categories, according to Rowley, are the basis of a strong KM program. Rowley is careful to draw attention to the level of diversity in the field of KM and the various ways KM can be facilitated and developed. She is also clear in stating that the knowledge that is included in KM programs is both explicit and tacit, as the field encompasses many different areas, though it is most commonly limited to being conceptualized as a tool for businesses. Using Rowley's four categories as a way to understand the purpose of KM, this paper will explore the ways in which Jeremy Dutcher's 2018 album "Wolastoqiyik Lintuwakonawa" is an example of KM. Dutcher's album deals with the traditional knowledge of the Wolastoq people. The album is an "exploration" (Jeremy Dutcher, 
2018) of Dutcher's own Wolastoq roots, and a painstaking project undertaken to unite the past and present together in musical form.

\section{Traditional Knowledge}

Traditional Knowledge (TK) is typically thought of as the knowledge Indigenous People have accrued over millennia that informs their interaction with the environment they inhabit. Typically, TK is conceptualized as a form of ecological knowledge, with Indigenous People having a complex and detailed understanding of the natural process of the environment which surrounds them, even if their understanding lacks a scientific foundation (Gloade, 2018). This knowledge is formed via generations of observation and interaction; it is an experiential and practical knowledge. It is this aspect of TK that is most relevant to the subject of this paper. TK is knowledge accrued through interaction, both with the environment and other members of a community. In the article "Traditional knowledge management and preservation: Intersections with Library and Information Science", Charles Maina offers a definition of Traditional Indigenous Knowledge that conceives of TK as a "dynamic and changing" (Maina, 2012, p.16) knowledge that is the result of Indigenous People interacting with each other and their environment. Maina's definition is one which removes the restrictions of ecological knowledge from the concept of TK; instead, Maina allows that TK is transmitted orally, and is something which is impossible to declare "past knowledge" (Maina, 2012, p.16). TK is not the stuff of historical study, but rather is a way of understanding and contextualizing the world in which one lives. In the case of Dutcher's album, this knowledge includes both the music he creates and participates in, and the language in which he sings.

Music is an essential part of $T K$, if it is accepted that TK expands to include ways of interacting with others. Music is often social, it is a place of togetherness and common understanding, and, most importantly, it is communal. This communal aspect of music is both reflexive and generative. Music is a way of holding on to past events and histories, honouring dead, partaking in religious ceremonies and participating in a culture. Often, the knowledge imparted by music, knowledge which allows for a transmission of values, is one which becomes internalized. In religious music, for example, while a Christian might feel moved and understand the message and values imparted by the song "Abide with $\mathrm{Me}$," someone unfamiliar with Christianity would not understand the deeper meaning and comfort the song can provide. The words and their meaning escape an unfamiliar listener, but the musical accompaniment and emotionality of the performer can help to gain something approaching an understanding. An audio recording of "Abide with $\mathrm{Me}^{\text {" can }}$ be used to help facilitate this understanding in unfamiliar listeners and aid familiar listeners in remembering the 
values and lessons of the song, as well as help them feel connected to an overall sense of community. These values and lessons, are communicated via the song and are passed through generations orally, in exactly the same way Traditional Knowledge is.

\section{Music as Knowledge}

The next question that has to be asked is, "Is music knowledge, beyond being a way to communicate knowledge? Can the music in and of itself be a form of knowledge?"

In a 1996 article, David J. Elliott proposed a way of conceiving music, the creation and performance of it, as a form of knowledge. Music for Elliott is both an act of knowledge creation and participation, as well as utilization. Elliott acknowledges that these terms are "slippery at best" (1996, p. 21), as the concepts are inherently nonconcrete. Elliott goes on to posit that "music's status as a source of knowledge might be considered its primary value" (Elliott 1996, p. 21). In the case of Indigenous music, and specifically Dutcher's album, this knowledge is not just contained in the content of the songs, but the songs themselves are a form of knowledge, as is Dutcher's performance of them. Elliot states that to act intentionally is "to do something knowingly" (Elliott, 1996 p. 25), so for Dutcher to engage in the music of his people, to consciously decided to interact with the traditional music of the Wolastoq people, is to do it with knowledge, both as part of the process and as the eventual goal. Dutcher's knowledge of the music, of the Wolastoqey language, and his own knowledge as a musician are enacted and manifested in the album. At the most basic level, Dutcher's musical production of the album is an act of knowledge creation, he is adding to the knowledge base of Indigenous music as well as to the broader body of Canadian music. In his utilization of his skills as a musician, Dutcher is enacting Elliott's assertion that knowledge in music is not restricted to words and symbols, but is "manifested in doing" (Elliott, 1996 p.26).

The performance of a musical selection, be it via instrument or vocally - both of which Dutcher can do - is the manifestation of his knowledge. For Elliott, intentional actions are the "practical, non-verbal" (Elliott, 1996 p.26) manifestations of thinking and, indeed, knowing. The participation in a performance of a piece of music is the engagement in the knowledge of the music; the personal knowledge of the performer the technical aspects of a musician's skill and the overall knowledge of the piece. In the case of Dutcher, performing songs from his album involves knowledge at the level of his own skill as a musician and performer, and interacting with the knowledge of the song as a cultural item. The meanings of the music, the emotionality that can be encoded into the music, the pronunciation of certain words and phrases, these are knowledge aspects of the music that are explicit. The technical aspects of the musical performance are, if Elliott's definitions are to be accepted, an 
enactment and manifestation of knowledge. Therefore, Dutcher's album and any subsequent performance of the selections from his album are likewise, manifestations of knowledge.

The context of KM in traditional knowledge is, as previously stated, usually ecological in nature. In the documentary "Guardians of Eternity", the use of traditional knowledge is debated as a means to share and communicate information about Giant Mine and the environmental dangers its waste disposal procedures pose traditional means of knowledge and information sharing are, in this instance thought of as a tool. Oral culture and stories are suggested as a means to ensure that the information and knowledge about the commitment needed to maintain the mine is passed intergenerationally for the thousands of years required in the mine's upkeep. Gerald Gloade, an educator at the Mi'kmawey Debert Cultural Centre, recently spoke at a conference that highlighted the access to Indigenous Knowledge. In the course of his hour-long talk, Gloade discussed the ways Mi'kmaq people understand their environment, and the natural processes of the world around them. Gloade highlighted the way traditional knowledge of the natural world informed Mi'kmaq interactions with the land they live on, notably how there was a time for swimming; this time is after the July thunderstorms have shocked and clarified the pond water, and the tadpoles have hatched (Gloade 2018). He highlighted that, while science describes the process as the splitting of atoms, to the Mi'kmaq people, the difference is just an understanding, garnered over thousands of years of living with the environment. This understanding is precisely the category of TK that is so hard to pin down. While the facts of the issue are clear - lightning adds ozone to the water in the summer and cleans it, these are not the facts as the Mi'kmaq people would have understood it, with their westernized jargon. Instead there is an understanding of time; after a certain time, the water is clean and people entering the waterbody will not harm anything else using the pond to live. Knowledge such as this becomes cultural - I have lived in Nova Scotia and swum in lakes and ponds all of my life, but I have never encountered this knowledge about summer storms cleaning the water bodies, or that my presence in the water before July could be harmful to the water body's ecosystem. The knowledge that Gloade shared in his talk, however, is a perfect example of traditional knowledge; it is a way of interacting with and understanding the world they inhabit. This knowledge is not specific to the Mi'kmaq people, it applies to anyone who interacts with the environment, but it is their knowledge, curated and shared through the generations of their people.

\section{Case Study: Wolastioqiyik Lintuwakonawa}

Dutcher's album Wolastioqiyik Lintuwakonawa is an effective form of knowledge preservation, sharing, and even creation. Jennifer Rowley's third 
responsibility of $\mathrm{KM}$, which involves an enhancement of the knowledge environment, which allows for the creation and sharing of knowledge is undeniably applicable to Jeremy Dutcher's debut album. The music of the album is in the Wolastogey language, which is a dialect of the Maliseet-Passamaquoddy language family (Government of New Brunswick, 2018). The lyrics and melody are traditional; they can easily be mapped onto the selections of the wax recording Dutcher built into his tracks. The musical composition, which features traditional drums and instruments as well as a standup bass and a piano. Built into the tracks alongside the wax recordings, Dutcher has an interview with an unnamed elder who discusses her remembrances of her earlier life and how Dutcher's music will "bring the people back" (Jeremy Dutcher, "Epqahak", 2018). The Wolastoqiyik, now referred to as Maliseet live along the Saint John River. According to government reports, around 4000 Wolastioqiyik reside in New Brunswick while there are another 1,500 in Quebec and Maine (Government of New Brunswick, 2018). Of these some 5000 people, it is estimated that roughly only 100 people still speak Wolastoqey, and those are primarily elders. It is a language that is scarce, but not dying, despite the attempts by the Canadian Government to eradicate Indigenous languages. In Dutcher's own words, he struggles "to talk about languages dying" (Grier, 2018, pp.1). The language has always been in the songs, he says, and the songs have never left. He lets the work of his elder Maggie Paul guide his work in the project to bring the music and language back. That Wolastoqiyik Lintuwakonawa is in Wolastoqey is a further help to bringing back a language that "had to go away for a little while, for safekeeping" (Grier, 2018, pp. 2). The songs are presented in Wolastoqey, in the digital album there is a very small write-up describing two or three of the tracks, but no formal translations or explanations are provided. The only English to be found is in the interview between Dutcher and the elder.

This lack of English translation does not detract from the experience or, in fact, the beauty of Dutcher's album. An incredibly technically knowledgeable performer, Dutcher is able to communicate the emotion through his compositions and vocal performances. To see him perform live and witness the way Dutcher's entire body is overtaken by the effort to create and perform the music, is a privileged experience. If the conversation about music and knowledge stopped at a technical viewpoint, with Elliot's argument about the creation of knowledge in musical performance being the end goal of this paper, viewing Dutcher's face as he sings, watching him move his body to coax the best possible sound from his voice would be proof enough. His accompanying instrumental arrangements further this point.

Dutcher's album is the culmination of five years of anthropological work. The 
aforementioned cylindrical recordings are the 110-year-old recordings of Dutcher's own ancestors from the Canadian Museum of History (Brocklehurst, 2018, pp.10). By taking these existing documents and interacting with them, by introducing them to the popular conscience, Dutcher has played an essential role in the process of KM. He has made that information available in a way it was not before - his album is $\$ 7.99$ on iTunes and has garnered national attention with his recent win of the 2018 Polaris People's Prize (Brocklehurst, 2018, pp.1). The album does the work of taking explicit knowledge, knowing which songs are sung as lullabies and honour songs, what songs are meant to celebrate marriages, and making that knowledge tacit. The tacit nature of the music comes from the sheer emotionality of Dutcher's performance. The album is a teaching tool, it helps to instruct, though perhaps "inform" would be a more accurate word to use in this instance, people of the musical life of the Wolastoq people. This, in turn, is the beginning of learning about the Wolastoqiyik people as whole. The album also provides examples of the Wolastoqey language, the phonetics of the people who speak it, and transmits that knowledge to those who listen to the album. Dutcher describes Indigenous people as being "hungry for language, because it's a rather recent phenomenon for it to be taken away from the community and we want it back" (interview). In his album, Dutcher is working towards that reclamation.
This conviction is supported by the interview between Dutcher and the unnamed female elder that is the focus of the third track of the album entitled "Eqpahak" - what follows is a transcription of said interview:

Female Elder (FE): I think about that sometimes; I'd like to learn all the songs that the people - that the people sang here. I'd like to listen to those and sing those. People will be singing; you know?

Dutcher: Yeah

FE: There's not only me, there's a lot of people bringing those songs back. And when you bring the songs back, you're gonna bring the dances back, you're gonna bring the people back, you're gonna bring everything back.

Dutcher: Yeah

FE: It'll be just like when we, when we first started. We brought the music back, we brought the drum back, sweat lodges are here, tipis are going all over the place, wigwams, people are making wigwams... (unintelligible)

Dutcher: So you think music had a lot to do with that?

FE: Oh you got that right *Dutcher laughs* Yeah, it sure does!

Dutcher: Really?

FE: Music will bring youth - because - the same way when you sing, when you sing your songs (Jeremy Dutcher, "Eqpahak", 2018, 0:00-0:59). 
The interview fades here into Dutcher's piano accompaniment and vocal recordings. Regardless, the meaning is clear. Dutcher's album and work are an essential part of the knowledge preservation and management of the music and life of the Wolastoqiyik people. His music, from a technical standpoint is a form of knowledge management in its ability to preserve and introduce new people to the music of his ancestors. Dutcher's album is also a way to "honour those who came before us" (Dutcher in a live performance at Halifax Pop Explosion 2018) and to "lay the footwork for those who have yet to come" (Brocklehurst, 2018, pp.8). His music forms a conversation between the past and present in a way that is both touching and technical, at once a labour of love for his heritage and ancestors and a stunning display of Dutcher's own technical skill. Dutcher also brings the concept of Etuaptumumk into the fold of his music. The western composition style, with its traditional orchestra. instruments and his own vocals, and Wolastoqiyik melodies mean the two musical styles are in a constant conversation. Incidentally, the western style accompaniment serves to make the music more familiar to ears that are not used to the Wolastoqey language. This duality means the music is further reaching and can be enjoyable by a broader audience base. The marriage of the two senses of music is supremely successful, and yet another area where Dutcher displays a depth of knowledge. Dutcher is not the only Indigenous musician to record the traditional music of his people, he enters a long line of similarly minded artists. A Tribe Called Red and A Tribe Called Mi'kmaq are both musical groups who record traditional songs using drum work and vocals to make the music of their people more accessible. Across the country and in other parts of the world as well, many First Nations and Indigenous peoples are aiming to "preserve their languages through art" (Grier, 2018, pp. 6). Dutcher's album has contributed to this effort of knowledge preservation, which is, again, one of Rowley's top goals for knowledge management.

\section{Perspectives on Traditional Knowledge and Music}

In the case of Rangwato Magoro, there are similarities to Dutcher's musical project. The author of this case study, Mogomme Aplheus Masoga, recounts how during a workshop in the early 2000's, he encountered a troupe of performers. When he asked them about the song and dance they had recently displayed, the malende, and what it was, they described it as "music in the complete sense" (Masoga, 2007, p.281). This approaches Elliott's concept of music itself as knowledge. Masoga goes on to describe how, for many African Indigenous people, music is an integral part of social interaction. He further asserts that African Indigenous music plays a major role in the politics and general intelligence of everyday life of people (Masoga, 2007, p. 281). The Tshivenda performers' concept music can "encompass all the life which surrounds the music" (Masoga, 2007, p. 
281). The day-to-day interactions between people and the environment, and people and other people, everything that creates sound as a result of human action, could be considered music. Pairing this conception of music as the result of lived actions, or actions undertaken knowingly, become music. Music, according to Elliott, is also actions done knowingly - the common denominator in this situation is knowledge. Life becomes the subject of music; music is knowledge enacted in life, according to this, music and knowledge are inextricably intertwined. Music in this case exceeds the bounds of entertainment and becomes reflective of a way of life, and of life itself. Music here becomes a way of understanding the climate, if you will, of a society.

Masoga's article goes on to discuss his experiences interviewing the Sepedi African woman Rangwato Magoro who teaches and performs a traditional musical style 'Mmino wa Koša' (Masoga 2007, p.281). Magoro, teaches musical style alongside a more westernized school curriculum. The students spend the morning in the western style school and then in the afternoon they learn from Mme. Magoro. Masoga remarks on the comfort the "young scholars" (Masoga, 2007, p.284) feel switching between the two learning and teaching environments. In his article, Masoga has encoded an interview with Mme. Magoro, wherein she discusses the way she can use the traditional music and dances to instruct her students. While the music and dance is in itself a learned skill, Masoga also discusses the way that the songs can be used to teach young girls to avoid the "dark things" and "social ills like HIV/AIDS, childabuse and rape" (Masoga, 2007, p.289). The two styles of teaching and knowledge imparting are in conversation with each other. Mme. Magoro also discusses the way, when she creates new songs, it is an interaction with her.

More relevantly, Mme. Magoro is quoted as saying "we sing and dance about life, and moreover, music is life" (Masoga 2007, p. 287). As Masoga describes it, the music, dancing and drumming should be viewed as providing a realistic representation of life (Masoga, 2007, 288). The music Mme. Magoro composes is another form of knowledge use. Both Masoga and Mme. Magoro emphasize the fact that she does not view herself as a composer in the western sense of the word - a musician who arranges the music of composition, but rather as "a conduit for her ancestors" (Masoga 2007, p. 288). To describe this process, Mme. Magoro uses the term "mohlami wa kośa", a Sedepi phrase which means "someone who makes something from nothing" (Masoga, 2007, p. 288). This, like so much of the Masoga article, is in alignment with Elliott's assertion that music is a form of knowledge. Unlike Elliott, whose focus on the knowledge aspect of music is technical, Mme. Magoro's musical experience of knowledge seems to be rooted in life experience. The article regarding Mme. Magoro's experience of 
music as knowledge, creates the impression that, similarly to Elliott's thesis (in this case of life experiences both of herself, her students, and her ancestors) music is inextricable from a concept of knowledge. Further, Mme. Magoro, in her use of traditional forms of musical knowledge to educate children has managed to find a place of conversation and convergence between western knowledge and Traditional Knowledge.

It is precisely this place of conversation that Dr. Elder Albert Marshall and Dr. Cheryl Bartlett discuss in their concept of "TwoEyed Seeing" or "Etuaptumumk" in Mi'kmaq (Marshall \& Bartlett, 2018). The concept, which was coined by Elder Albert Marshall, proposes that one eye is used to see from an Indigenous or Mi'kmaq perspective, while the other sees from a Western perspective. This process of colearning and coexistence is something Elder Albert Marshall calls inherent, a dialogue between two opposed styles of learning and knowing. It is, Elder Albert Marshall attests, a "constant fine-tuning of perspective" (Marshall \& Bartlett, 2018). Elder Albert Marshall and Dr. Bartlett also stressed, that essential to TK is the concept that knowledge is physical as well as spiritual; in dealing with TK it is essential to "keep sight of the people" (keynote). Knowledge is a human based concept, and in the context of Dutcher's album, the sense of "emergence and community" (Marshall \& Bartlett, 2018) is paramount to this conception of knowledge.
Elder Albert Marshall's late wife, Elder Murdena Marshall once explained the concept of knowledge and community, and the way it relates to the Mi'kmaq people as "we are, therefore I am" (Marshall \& Bartlett, 2018). This of course, is a play on Descartes famous "I think, therefore I am" (Descartes, Section IV, pp. 1) In this conception, rather than intellectual process taking precedent in a person's existent, community and the knowledge generated by a community, knowledge of the world around them, music and emotional interactions, and the existence of the community are the defining matters of a person's existence. In this concept, the community is inextricable from a person's experience. As previously stated, music is a communal action, it creates knowledge of a community through teaching, presentation of values and music has an undeniable ability to reflect the identity of the people who make the music.

The concept of Etuaptmumk is a tool which can help bridge the gap between Western knowledge and learning, which takes the structured view of the ' 5 W's': who, what, when, where, and why? While TK takes a more dynamic and fluid approach to learning, as so much knowledge is dependent on the knowledge teller, who is responsible for the sharing of the knowledge. This dynamism means that participation in TK is essential, it is how the knowledge is preserved and shared. To caveat this, it is important to remember that knowledge is incredibly specific to the community which produced it. While it is 
possible to discuss the role of music in sharing knowledge of a community, the specifics of that knowledge and what it means for the people who created the music, and continue to produce it, is incredibly specific. Etuaptmumk is applicable to many different Indigenous learning styles, and many intercultural learning styles, the eye which sees in the non-western manner is specific to that culture. Likewise, while an album similar to Dutcher's is possible among other Indigenous peoples, and many do exist, Dutcher's album is specific to the Wolastoq people. His music cannot be interpreted as applicable to other people's knowledge, the music and knowledge of the album is Wolastoq knowledge.

\section{Traditional Knowledge and Information Professionals}

The role information professionals play in helping to preserve Traditional Knowledge (TK) and help facilitate the sharing of TK is, of course, important. This relationship is tricky to navigate, as it is paramount that the voices of said information professionals not be louder than those of Indigenous People, or that these professionals not take up Indigenous space. With this caveat of respect, Charles Maina argues that it is the responsibility of Library and Information Science (LIS) professionals to help create strategies and repositories for the storage and preservation of TK. Maina sees the prospect for LIS professionals to be involved in the preservation and access of TK via "collecting, preserving, and disseminating traditional knowledge [and] publicizing its value" (Maina, 2012, p.14). This is a project he calls for libraries to take the lead on, as the library institution is uniquely suited for this project, given the role of libraries as information and knowledge repositories. Naturally, there are fears and hesitancy surrounding this venture, as many in the LIS field are concerned about the clash between Indigenous concepts of knowledge and western library values; there is further concern rooted in the concept of sacred knowledge and the democratization of library catalogues (Maina, 2012, p.17).

It is important to mention is that there are projects in place to preserve and educate people on Indigenous music and Indigenous Traditional Knowledge. Library and Archives Canada has an extensive online resource for information on the instruments and musical stylings of First Nations, Inuit, and Metis peoples. While interesting, and in its own way useful, this is very much an information repository and information page, and not a place of knowledge sharing. The webpage can provide the technical information on how the music was produced or what it sounded like, or the emotions and social context of the music. More effectively, the online platform Mukurtu, is a space for Indigenous communities to upload, share, and exchange their digital heritage. While not Canadian, Mukutu is the result of collaboration with a Warumungu elder, Washington State University, the National 
Endowment for the Humanities, and the Institute of Museum and Library Services (Mukutu, 2018). This online repository gets closer to the type of knowledge sharing Maina has in mind, with the homepage of the website highlighting the focus on "ethically-minded" sharing of the knowledge and information (Mukutu, 2018), even if it still is in the incubation stage. Other institutes have taken up the responsibility of preserving indigenous knowledge in conjunction with indigenous control of the information. The Beaton Institute, in Cape Breton University, is home to an extraordinary amount of material on Mi'kmaq and Eskasoni history, life, and knowledge, including video recordings, images, and audio transcripts. This online archive is useful for archival material, but very little context is given to the images or the data files. The videos and recordings do make the knowledge and information more accessible, that cannot be denied, but they are not part of the popular conscious.

\section{References}

Bartlett, C. \& Marshall, A. (2018).

Reconciliation in Canada today: considerations on Etuaptmumk /Two-Eyed Seeing and integrative science. In proceedings of the Indigenous Knowledge and Access Symposium. Dalhousie University, Nova Scotia, Canada.

Brocklehurst, S. (2018, September 18). 'Deep listening': How Jeremy Dutcher crafted his fascinating
Polaris Prize-winning album. CBC News Profile.

DesCartes, Rene. (2001). Discourse on the method of rightly conducting the reason, and seeking truth in the sciences. Retrieved from: http://www.gutenberg.org/files/59 /59-h/59-h.htm.

Dutcher, J. (2018) Wolastoqiyik Lintuwakonawa [CD]. Canada: Jeremy Dutcher/ Fontana North.

Dutcher, J. (2018) Eqpahak. On Wolastoqiyik Lintuwakonawa [CD]. Canada: Jeremy Dutcher/Fontana North.

Elliott, D.J. (1991). Music as knowledge.

The Journal of Aesthetic

Education, 25(3), 21-40. Retrieved from

https://www.jstor.org/stable/33329 93

Gloade, G. (2018). Glooscap legends, oral histories, and our cultural memory timeline. In proceedings Symposium for Indigenous Knowledge and Access. Library and Archives Canada and Dalhousie University.

Government of New Brunswick, (2018). Wolastoqiyik portrait of a people. In Tourism, Heritage and Culture (Government of New Brunswick). Retrieved from: https://www2.gnb.ca/content/gnb/ 
en/departments/thc/heritage/cont ent/archaeology/Wolatoqiyik.html

Grier, C.V. (2018, August 24). How musicians are keeping endangered languages alive: From Yiddish to Garifuna to Wolastoqey, these artists are preserving their languages through song. Now Magazine

Guardians of Eternity. (2015). Retrieved from

http://www.guardiansofeternity.ca/

Maina, C.K. (2012). Traditional knowledge management and preservation: Intersections with library and information science. International Information and Library Review, 44(1), 13-27.
Masoga, M.A. (2007). Rescuing archives of indigenous knowledge for contemporary musical arts: the case of Rangwato Magoro. Fontes Artis Musicae, 45(3), 280290. Retrieved from http://web.a.ebscohost.com/ehost/ detail/detail?vid $=0 \&$ sid $=f 564 c 69 a-$ $795 d$ -

4652a21dfa181d93a8d7\%40sdcses smgr04\&bdata $=J n N p d G U 9 Z W h v c$ 3QtbGI2ZQ\%3d\%3d\#N=26023456 $\& d b=a p h$

Murkutu, (2018). About. Retrieved from: http://mukurtu.org/about/

Rowley, J. (1999). What is knowledge management? Library Management, 20(8), 416-419. Retrieved from http://ezproxy.library.dal.ca/login? url=https://search-proquest com.ezproxy.library.dal.ca/docview /198867999?accountid=10406 